Bangladesh J. Sci. Res. 27(2):165-174, 2014 (December)

\title{
RESPONSE AT DIFFERENT GROWTH STAGES OF SOYBEAN TO DEFICIT IRRIGATION CONDITION
}

\author{
Shakil Uddin Ahmed*, Masateru Senge ${ }^{1}$ and Kengo Ito ${ }^{1}$ \\ Department of Soil, Water \& Environment; University of Dhaka \\ Dhaka-1000, Bangladesh
}

\begin{abstract}
An attempt was made to assess the effect of deficit irrigation on yield components at individual growth stages of soybean [Glycine max (L.) Merrill]. The deficit irrigation treatments were 0 - 25, 25 - 50, 50 - 75 and 75 - 100\% of total available water (TAW). Evapotranspiration was dominated in order by: Flowering $>$ pod formation $>$ development $>$ maturity stage. Water stress coefficient (Ks) or ETa/ETm at Flowering and Pod formation stages were too strong to be tolerated due to the effect of high evapotranspiraton rates. Both water use efficiency (WUE) and yield efficiency (YE) was also very sensitive under water stress conditions at flowering and pod formation stages. Available water deficit level lower than $50-75 \%\left(D_{3}\right)$ throughout the different growth stages of soybean was good enough for calculating the yield response factor $(\mathrm{Ky}=0.87)$, and both WUE and YE was higher at $50-75 \%$ of TAW $\left(\mathrm{D}_{3}\right)$ than the full irrigation $\left(D_{1}\right)$. It may be concluded that deficit irrigation was effective $\left(K_{y}<1\right)$ for economy of water usage under water deficit lower than $50-75 \%$ of TAW $\left(D_{3}\right)$. It reveals from the results that to get a good yield of soybean under limited supply of irrigation water it is better to avoid moisture stress at the reproductive stage (flowering and pod formation) of the crop.
\end{abstract}

Key words: Crop water requirement, water stress coefficient, water use efficiency, yield efficiency and yield response factor.

\section{Introduction}

Soybean crop is traditionally a non-irrigated (rain fed) crop that occupies quite an extensive area in agro ecosystems. Improvements in yield efficiency of crops through water use efficiency are essential under the scenarios of water scarcity predicted by global climatic changes. Current climatic conditions and when irrigation sources are limited and costly, deficit irrigation at individual growth stages may help avoid crop stress at critical times. For a full evaluation of the effect of limited water supply on yield, consideration must be given to the effect of the limited water supply during the individual growth periods of crops. Scheduling of the supply is based on minimizing water deficits in the most sensitive growth periods. During periods of unpredictable water shortages

\footnotetext{
"Corresponding author: shakil@du.ac.bd. 1'Graduate School of Agriculture, Faculty of Applied Biological Science, Gifu University, Yanagido 1-1, Gifu City, Japan.
} 
within a season, adjustments of water scheduling must be made in relation to the difference in yield response to water deficits on the crops and their individual growth periods (Fagi and Tangkuman 1985).

According to Doorenboss and Kassam (1979), the effect of water stress on yield is quantified by relating the relative yield decrease to the relative evapotranspiration deficit through an empirically derived yield response factor $\left(\mathrm{K}_{\mathrm{y}}\right)$ :

$$
1-\frac{Y_{ \pm}}{Y_{m}}=k, \times\left(1-\frac{E T_{ \pm}}{E T_{m}}\right)
$$

where: $\mathrm{Y}_{\mathrm{a}}=$ Actual yield (kg/ha), Ym = Maximum yield (kg/ha) $\mathrm{ET}_{\mathrm{a}}=$ Actual evapotranspiration (mm), $\mathrm{ET}_{\mathrm{m}}=$ Maximum evapotranspiration $(\mathrm{mm}), \mathrm{Ky}=$ Yield response factor.

According to Kirda et al. (1999), the main approach in deficit irrigation practice is to increase crop water use efficiency by partially supplying the irrigation requirement and allowing water stress to planned plant during one or more periods of the growing season with the least impact on crop yield. The Ky of soybean for the whole growing period under water deficit was 0.85 according to Doorenboss and Kassam (1979).

Water management means that water allocations of a controlled but limited supply would be directed toward meeting the full water requirements of the crop during the most sensitive growth periods for water deficit rather than spreading the available limited supply to the crop equally over the total growing period (Boyer 1982). According to Moutonnet (2000), the Ky values for most crops are derived on the assumption that the relationship between relative yield $(\mathrm{Ya} / \mathrm{Ym})$ and relative evapotranspiration (ETa/ETm) is linear and is valid for water deficit of up to about 50 percent or 1- ETa/ETm $=0.5$.

Based on the above description, the research was conducted with the objective to investigate the influence of available water deficit on yield response at different growth stages of soybean, so that the deficit irrigation management for the individual growth stages can be made to ensure optimum growth and production of soybean.

\section{Materials and Methods}

This research was conducted in a vinyl house (surrounding sides were open) of the Gifu University, Japan. Soybeans (Glycine max (L.) Merrill) were planted in plastic buckets. The average temperature was $22.4^{\circ} \mathrm{C}$ and the relative humidity was $67.5 \%$ during experiment duration. The experimental design was a randomized complete block with four treatments and three replications. The physical, moisture and chemical properties of the soil are shown in Table 1. 
Table 1. Initial soil physical, moisture and chemical properties.

\begin{tabular}{lll}
\hline Physical properties & Moisture properties $\left(\mathrm{m}^{3} / \mathrm{m}^{3}\right)$ & Chemical properties \\
\hline Texture $(\mathrm{g} / \mathrm{g}):$ & Field capacity, $\theta_{\mathrm{FC}}(34.7 \mathrm{kPa}):$ & $\mathrm{pH}: 6.25$ \\
Sand $(0.63)$, & 0.350 & Organic matter: $0.095(\mathrm{~g} / \mathrm{g})$ \\
Silt $(0.20)$ and & Wilting point, $\theta_{\mathrm{PWP}}(185 \mathrm{kPa}):$ & Total carbon: $0.055(\mathrm{~g} / \mathrm{g})$ \\
Clay $(0.17)$ & $0.185 \quad$ Total nitrogen: $0.0035(\mathrm{~g} / \mathrm{g})$ \\
Textural class: Sandy loam & Total available moisture, & C/N: 15.9 \\
Particle density:2.49 $\left(\mathrm{g} / \mathrm{cm}^{3}\right)$ & $\theta_{\mathrm{FC}}-\theta_{\mathrm{PWP}} 0.165$ & Available phosphorus: 0.164 \\
Bulk density:1.07 $\left(\mathrm{g} / \mathrm{cm}^{3}\right)$ & & $(\mathrm{g} / \mathrm{kg})$ \\
Total porosity:0.57 $\left(\mathrm{m}^{3} / \mathrm{m}^{3}\right)$ & & Exchangeable potassium: \\
Three phase distribution & & $13.2(\mathrm{mg} / 100 \mathrm{~g})$ \\
$\left(\mathrm{m}^{3} / \mathrm{m}^{3}\right):$ & \\
Solid phase $(0.43)$, & & \\
Water phase $(0.35)$ and & & \\
Air phase $(0.22)$ & & \\
\hline
\end{tabular}

Available water was maintained at field capacity level during initial stage of 21 days after sowing (DAS) and total treatment period was 133 days (22 - 154 DAS), as development stage ( 22 - 43 DAS), flowering stage (44 - 63 DAS), pod formation stage (64 - 119 DAS) and maturity stage (119 - 154 DAS).

The water stress (D) with four levels of water deficit treatments imposed as $\mathrm{D}_{1}(0$ $25 \%), \mathrm{D}_{2}(25-50 \%), \mathrm{D}_{3}(50-75 \%)$ and $\mathrm{D}_{4}(75-100 \%)$ of available water deficit. The water deficit level of $\mathrm{D}_{2}(25-50 \%)$, for example, meant that the available water was maintained between $25 \%$ and $50 \%$ of total available water (TAW) throughout the growing season. When the maximum allowable depletion of available water got close to $50 \%$ of TAW, water was applied to restore the available water to the deficit level of $25 \%$ of TAW. TAW is defined as the water content between field capacity $\left(\theta_{\mathrm{FC}}\right)$ and permanent wilting point $\left(\theta_{\mathrm{PWP}}\right)$. The ranges of deficit irrigation treatment are shown in Table 2.

Table 2. The range of deficit irrigation treatment.

\begin{tabular}{cc}
\hline Water deficit level $(\%$ of TAW $)$ & Water content $\left(\left(\mathrm{m}^{3} / \mathrm{m}^{3}\right)\right.$ \\
\hline D1 $(0-25)$ & $0.350-0.309$ \\
D2 $(25-50)$ & $0.309-0.268$ \\
D3 $(50-75)$ & $0.268-0.226$ \\
D4 $(75-100)$ & $0.226-0.185$ \\
\hline
\end{tabular}

Diurnal soil moisture content was monitored by gravimetric method. Daily evapotranspiration (ET) was measured by the following formula:

$$
\text { ET: }\left(\mathrm{WD}_{\mathrm{i}-1}-\mathrm{WD}_{\mathrm{i}}\right) / \mathrm{Ac}
$$


where WDi is the weight of container at day (i) $(\mathrm{gm}), \mathrm{WD}_{\mathrm{i}-1}$ is the weight of container at day (i-1) (gm), and Ac is the surface area of the container.

Agronomic variables evaluated in this research were crop water requirement (CWR, g/pot), oven dry weight of total biomass including with roots (TDB, g/pot) and grain yield of soybean (Y, g/pot). CWR was equal to the total evapotranspiration during the irrigated period at individual growth stages of soybean. Daily evapotranspiration (ET), which determined the crop water requirement, was measured by weighing the container every day. The container served as the role of a weighing lysimeter that hydrologically isolates soil surface lateral inflow/outflow. Water use efficiency (WUE) was calculated as the ratio of total dry biomass to CWR at individual growth stages; and yield efficiency (YE) was calculated as the ratio of grain yield to CWR at individual growth stages of soybean.

Five seeds were planted in each plastic container (10 liters volume) with a diameter of $23.8 \mathrm{~cm}$, which had been filled with $10 \mathrm{~kg}$ air-dried soil, and one week later thinned to only 2 seedlings, which were maintained until the end of the growth period. Basal fertilizers (kg/ha) were applied at $20 \mathrm{~N}, 180 \mathrm{P}_{2} \mathrm{O}_{5}$ and $100 \mathrm{~K}_{2} \mathrm{O}$. All fertilizers were applied just once, at seedling stage. Statistical analysis was carried out using $\mathrm{F}$ test at $5 \%$ significant level and means were separated by LSD test.

\section{Results and Discussion}

Crop water requirement (CWR): CWR was equal to the total evapotranspiration during the irrigated period at individual growth stages of soybean. The influences of available water deficit (D) on crop water requirement at individual growth stages of soybean are shown in Table 3.

Table 3. The effect of available water deficit on crop water requirement (g) at individual growth stages of soybean.

\begin{tabular}{llccc}
\hline & \multicolumn{4}{c}{ CWR (g) at individual growth stage } \\
\cline { 2 - 5 } Treatment & $\begin{array}{c}\text { Development } \\
\text { 22-23 DAS }\end{array}$ & $\begin{array}{c}\text { Flowering } \\
\text { 44-63 DAS }\end{array}$ & $\begin{array}{c}\text { Pod formation } \\
64-119 \text { DAS }\end{array}$ & $\begin{array}{c}\text { Maturity } \\
\text { 120-154 DAS }\end{array}$ \\
\hline D1 (0-25\%) & $7276 \mathrm{a}^{*}$ & $19432 \mathrm{a}^{*}$ & $46184 \mathrm{a}^{*}$ & $11404 \mathrm{a}^{*}$ \\
D2 (25-50\%) & $5664 \mathrm{~b}$ & $15549 \mathrm{~b}$ & $32525 \mathrm{~b}$ & $11094 \mathrm{~b}$ \\
D3 (50-75\%) & $4828 \mathrm{c}$ & $12193 \mathrm{c}$ & $25530 \mathrm{c}$ & $7351 \mathrm{c}$ \\
D4 (75-100\%) & $3426 \mathrm{~d}$ & $8814 \mathrm{~d}$ & $20031 \mathrm{~d}$ & $4560 \mathrm{~d}$ \\
\hline
\end{tabular}

*Different letters represent the significant difference at level of 0.05 based on the LAD test.

It can be observed from this table that the effects of available water deficit on CWR are quite significant at level of 0.05 based on the LAD test. The table also shows that 
CWR at individual growth stages of soybean was lowered with increasing water deficit level from $\mathrm{D}_{1}$ to $\mathrm{D}_{4}$. It shows that CWR was highest in flower formation stage, followed by pod formation stage, advance stage, maturity stage and then initial stage. In general, crops are more sensitive to water deficit during emergence, flowering and early yield formation than they are during early (vegetative, after establishment) and late growth periods (Doorenboss and Kassam 1979). On the basis of above data, it can be presumed that soybean crops are more sensitive to water deficit during reproductive phase (flower formation and pod formation stage).

The relationship between crop water requirement at individual growth stages and total dry biomass of soybean are shown in Fig. 1. The gradient of the relationship was dominated in order of: flowering $>$ development $>$ pod formation $>$ maturity stage. It is indicating that biomass production was highest at flowering stage, since soybean crop height was stopped after flowering stage.

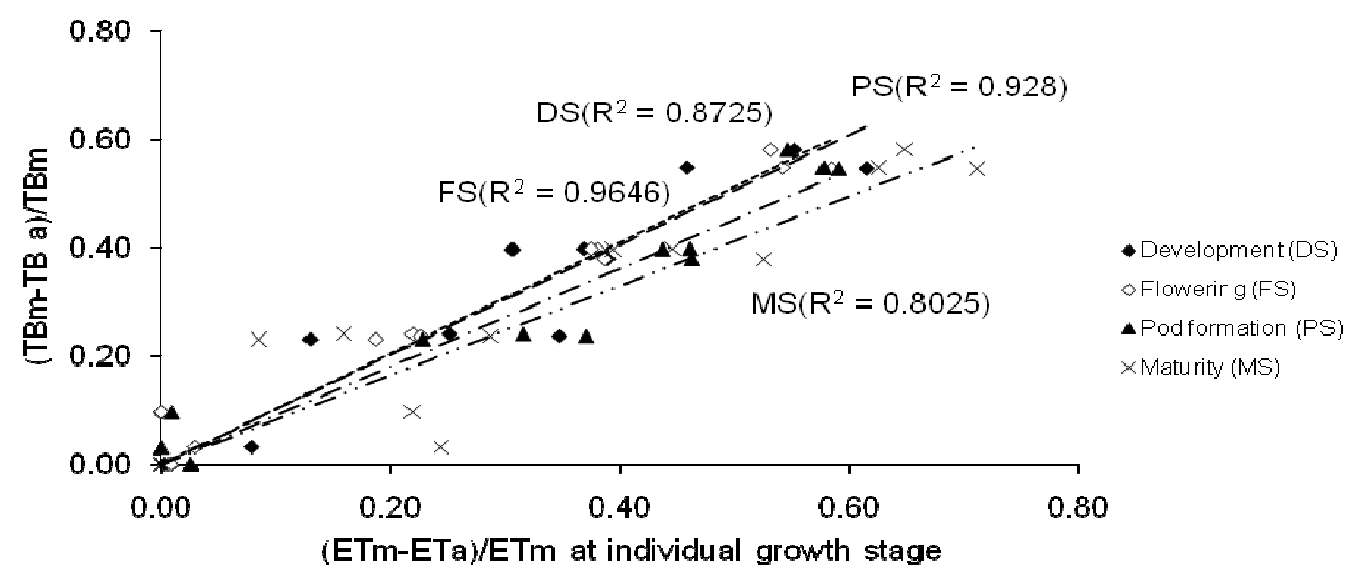

Fig 1 . The relation between total dry biomass and crop water requirement at individual growth stages of soybean under water deficit levels.

The relationship between crop water requirement at individual growth stages and grain yield of soybeans are shown in Fig. 2. The gradient of the relationship was dominated in order of: flowering $>$ development $>$ pod formation $>$ maturity stage. The relationship was also dominated in similar order of: flowering $\left(\mathrm{R}^{2}=0.9138\right)>$ development $\left(\mathrm{R}^{2}=0.8331\right)>>$ pod formation $\left(\mathrm{R}^{2}=0.7964\right)>$ maturity stage $\left(\mathrm{R}^{2}=\right.$ 0.7908). 


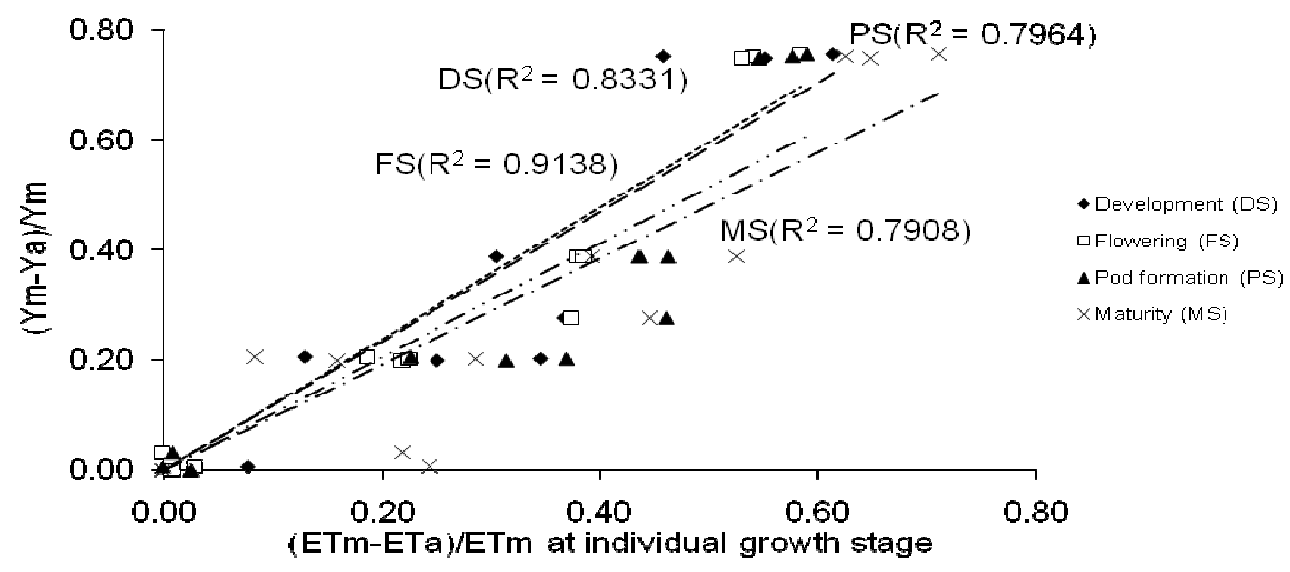

Fig. 2. The relation between grain yield and crop water requirement at individual growth stages of soybean under water deficit levels.

Water stress coefficient (Ks): According to Allen et al. (1998), the evapotranspiration under water stress condition is called as the adjustment evapotranspiration $\left(E T_{\text {cadj }}, \mathrm{mm} / \mathrm{d}\right)$ which can be calculated by the following equation.

$$
E T_{\text {cadj }}=K_{s} E T_{c}
$$

where $E T_{c}(\mathrm{~mm} / \mathrm{d})$ is the crop evapotranspiration under standard condition, $K_{s}$ is water stress coefficient (no dimension).

The value of $K_{s}$ is important for estimating $E T_{\text {cadj, }}$, so that the deficit irrigation scheduling can be made. $K_{s}$ describe the effect of water stress on crop transpiration (Allen et al. 1998). Assuming that the evapotranspiration at D1 (0 - 25\%) occurred under the ideal condition for plant growth in which the soil water content is near field capacity, and there is no limitation for plant to meet the maximum evapotranspiration (ETm), the actual evapotranspiration (ETa) at D1 is crop evapotranspiration (ETc), which means the evapotranspiration of plant under standard conditions (Allen et al. 1998). Water stress coefficient (Ks) is the ratio between the actual evapotranspiration and the maximum evapotrarspiration (ETa/ETm). The value of "p" is the ratio of water depletion to the total available water (TAW) in the root zone, which is an indicator of the water deficit level. For example, the average value of "p" under the water management of D2 (25 - 50\%) treatment is calculated as $(0.25+0.50) / 2=0.38$. $)$.

Fig. 3 shows the relation between water stress coefficient $(\mathrm{Ks}=\mathrm{ETa} / \mathrm{ETm})$ and the fraction of water depletion "p". The value of ETa/ETm is the ratio of the actual evapotranspiration (ETa) under available water deficit to the maximum evapotranspiration (ETm) at each growth stage, which is an indicator that the plant is in water stress condition (Ks). The value of $\mathrm{ETa} / \mathrm{ETm}$ is corresponding to the water stress coefficient proposed by Allen et al. (1998). 


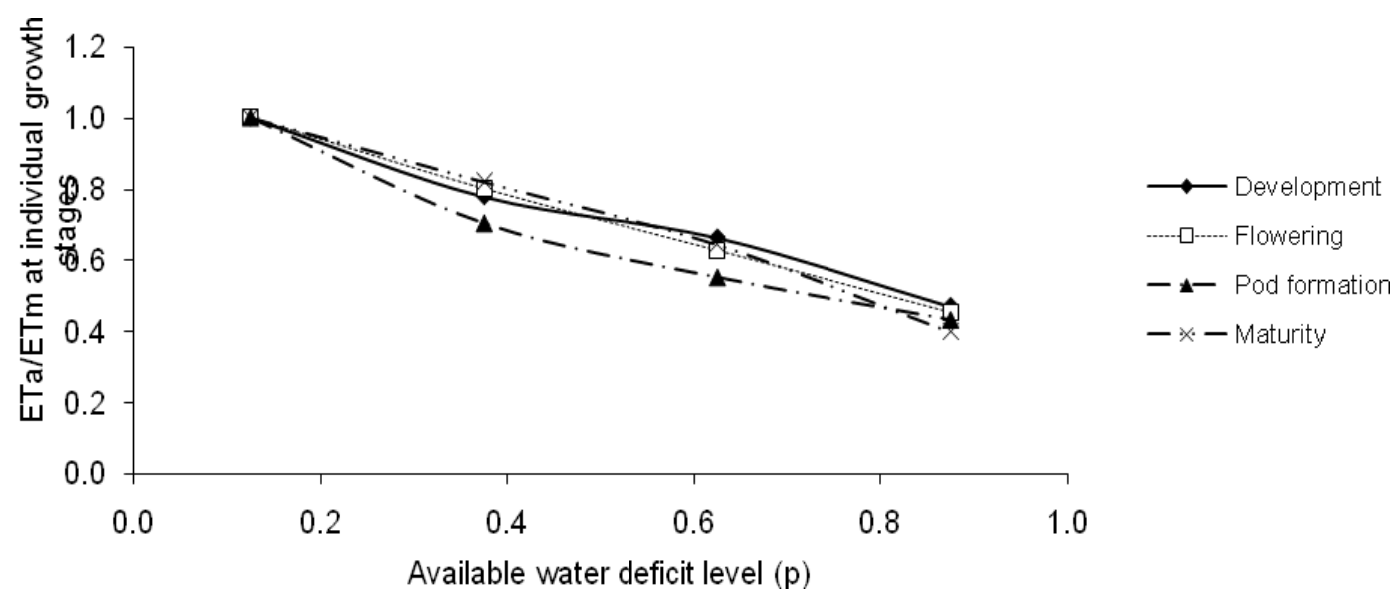

Fig. 3. The relation between the fraction of water depletion factors (p) and ETa/ETm at individual growth stages of soybean.

Fig. 3 also shows that the $\mathrm{K}_{\mathrm{s}}$ value is declining with increasing water deficit level "p". The decline was highest in pod formation, followed by flowering and then maturity and development stages. It means that the water stress condition at pod formation and flowering stages were too strong to be tolerated due to the effect of high evapotranspiration rate.

According to Doorenboss and Kassam (1979) when full water requirements are not met by available supply water, then $\mathrm{ET}_{\mathrm{a}}<\mathrm{ET}_{\mathrm{m}}$ or $\mathrm{ET}_{\mathrm{a}} / \mathrm{ET}_{\mathrm{m}}<1.0$. Based on this phenomenon, Fig. 3 shows that soybean was severely water-stressed under $D_{4}$, and the $K_{s}$ value of soybean varied depending on the growth stage and the available water deficit level.

Water use efficiency (WUE): Water use efficiency (WUE, g/g) is calculated as the ratio of total dry biomass (TDB, g/pot) to the crop water requirement (CWR, g/pot) at individual growth stages of soybean, which is shown in Fig. 4. Average WUE (g/g) value was dominated throughout the individual growth stages of soybean in order of: development (0.0218) > maturity (0.0139) > flowering (0.0083) > pod formation (0.0038) stage. It means that water stress condition was highest at pod formation stage and thereafter flowering stage.

WUE value is indicating that highest CWR has produced lowest biomass at pod formation stage and lowest CWR produced highest biomass at development stage, because of soybean crop height development was stopped at 49 DAS. WUE under available water deficit level of $\mathrm{D}_{3}(0.00400 \mathrm{~g} / \mathrm{g})$ at pod formation stage was 1.15 times as 
much as under full irrigation of $\mathrm{D}_{1}(0.00347 \mathrm{~g} / \mathrm{g})$. At flowering stage, WUE under available water deficit level of $\mathrm{D}_{4}(0.00840 \mathrm{~g} / \mathrm{g})$ was 1.02 times as much as under full irrigation of $\mathrm{D}_{1}(0.00825 \mathrm{~g} / \mathrm{g})$. So this experiment was good enough for increasing WUE under deficit irrigation management.

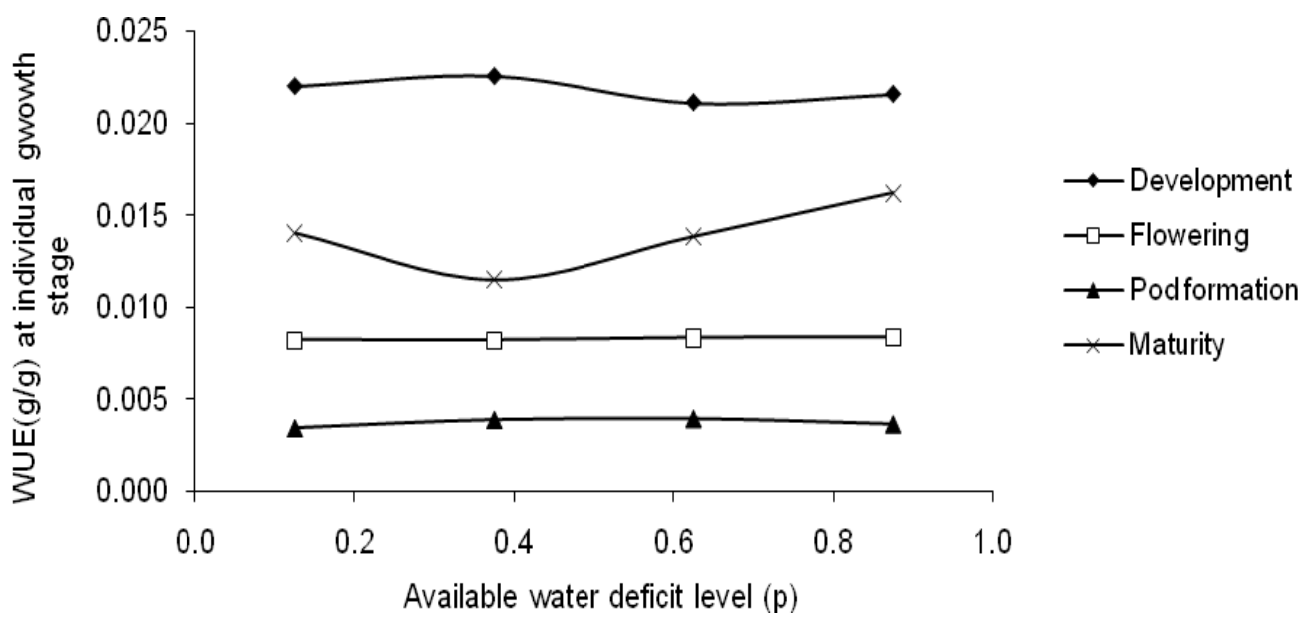

Fig. 4. The relation between the fraction of water depletion factors (p) and water use efficiency (WUE) at individual growth stages of soybean.

Yield efficiency (YE): Yield efficiency (YE) for water usage is calculated as the ratio of yield (g) of soybean to the crop water requirement $(C W R, g)$ at individual growth stages of soybean, which is shown in Fig. 5. YE value at individual growth stage increases slightly with increase of water deficit level from $D_{1}$ to $D_{3}$ and then deceased from $D_{3}$ to $D_{4}$, except at maturity stage. At maturity stage, $Y E$ decrease from $D_{1}$ to $D_{2}$ and thereafter increase from $D_{2}$ to $D_{3}$ and then again sharply decreased from $D_{3}$ to $D_{4}$. It is indicating that the deficit irrigation was not effective under 75-100 \% water deficit level $\left(D_{4}\right)$ and $Y E$ were very sensitive under water stress conditions at pod formation and flowering stages. YE under available water deficit level of $\mathrm{D}_{3}(0.00069 \mathrm{~g} / \mathrm{g})$ at pod formation stage was 1.19 times as much as under full irrigation of $\mathrm{D}_{1}(0.00058 \mathrm{~g} / \mathrm{g})$. It concluded that the deficit irrigation at $50-75 \%$ of TAW $\left(D_{3}\right)$ reduced the grain yield per unit area, but could conserve $9.9 \%$ of irrigation water to produce the same yield compared to the full irrigation $\left(D_{1}\right)$. 


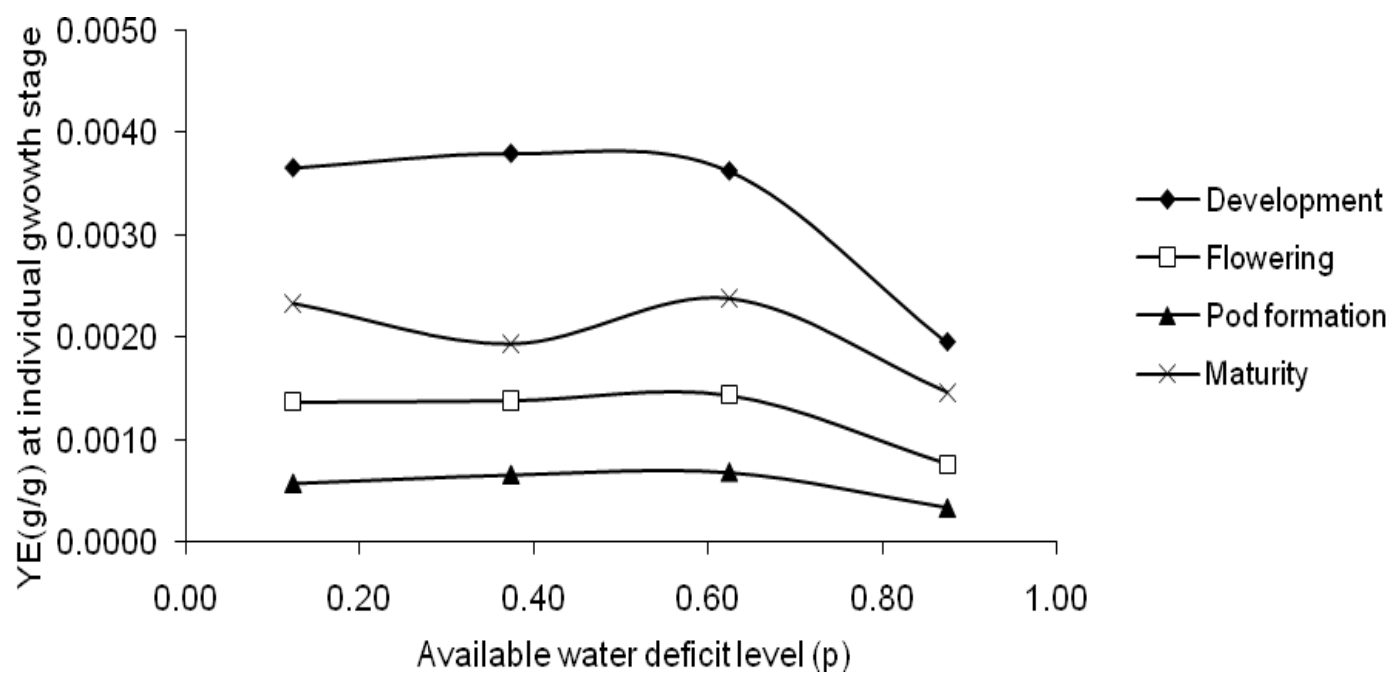

Fig. 5. The relation between the fraction of water depletion factors (p) and yield efficiency (YE) at individual growth stages of soybean.

Yield response factor (Ky): According to Fagi and Tangkuman (1985), the crop with higher $K_{y}$ value $\left(K_{y}>1\right)$ will suffer a greater yield loss than the crop with a lower $K_{y}$ value $\left(\mathrm{K}_{\mathrm{y}}<1\right)$. On the basis of this phenomenon, Fig. 3 shows that deficit irrigation was effective $\left(\mathrm{K}_{\mathrm{y}}<1\right)$ for economy of water usage under water deficit lower than $50-75 \%$ of TAW $\left(D_{3}\right)$. It means that deficit irrigation under water deficit at $75-100 \%$ of TAW $\left(D_{4}\right)$ was not effective $\left(\mathrm{K}_{\mathrm{y}}<1\right)$.

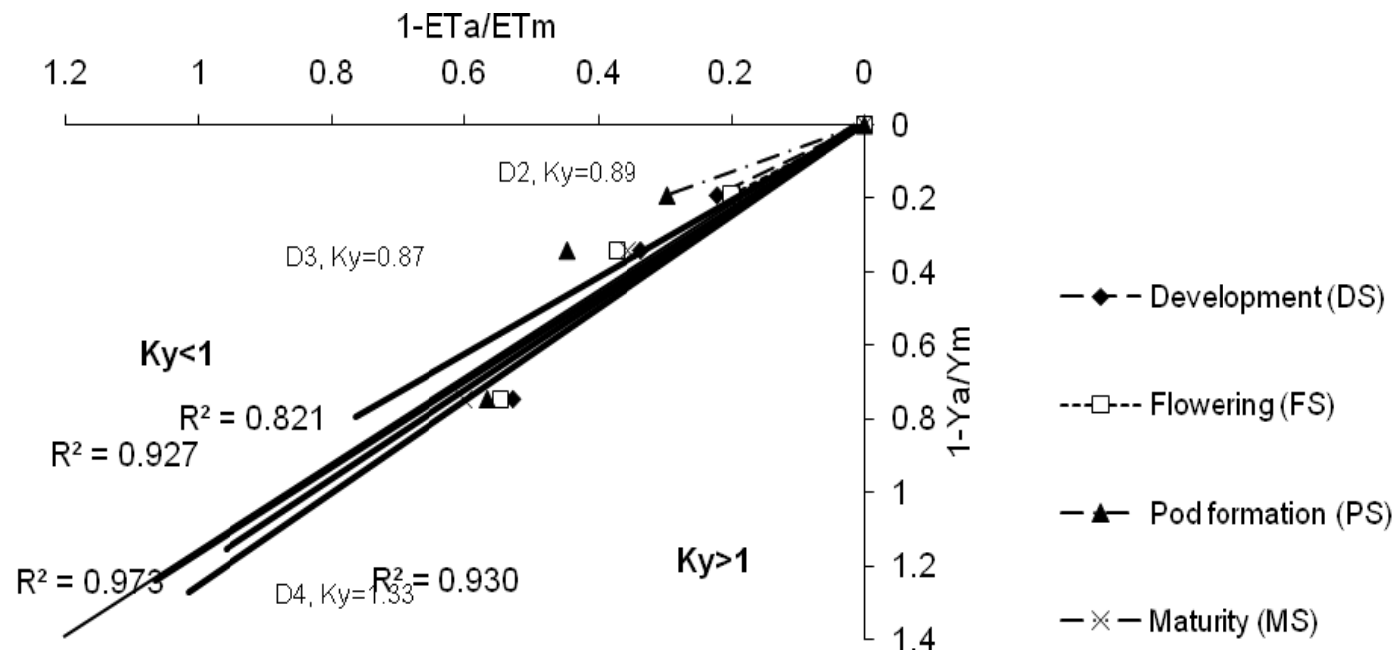

Fig. 6. The effect of available water deficit levels on yield response factor (Ky) at individual growth stages of soybean. 


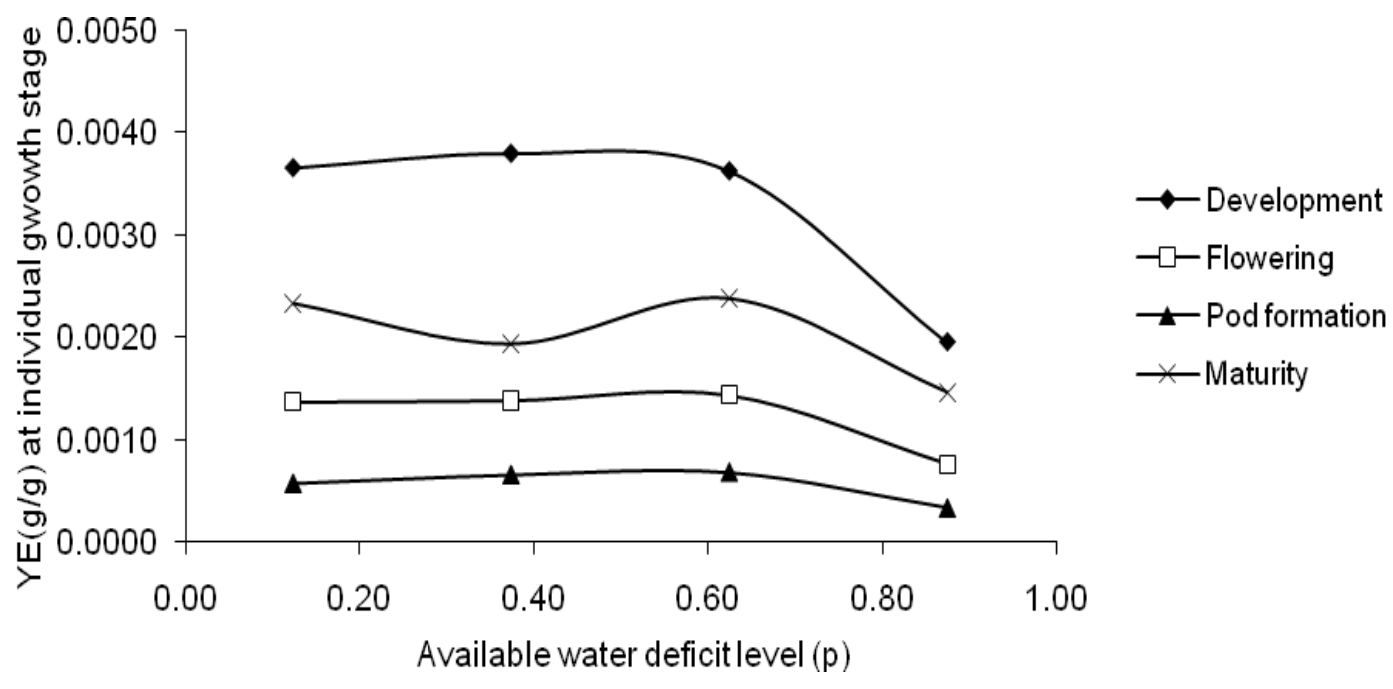

Fig. 5. The relation between the fraction of water depletion factors (p) and yield efficiency (YE) at individual growth stages of soybean.

Yield response factor (Ky): According to Fagi and Tangkuman (1985), the crop with higher $K_{y}$ value $\left(K_{y}>1\right)$ will suffer a greater yield loss than the crop with a lower $K_{y}$ value $\left(\mathrm{K}_{\mathrm{y}}<1\right)$. On the basis of this phenomenon, Fig. 3 shows that deficit irrigation was effective $\left(\mathrm{K}_{\mathrm{y}}<1\right)$ for economy of water usage under water deficit lower than $50-75 \%$ of TAW $\left(D_{3}\right)$. It means that deficit irrigation under water deficit at $75-100 \%$ of TAW $\left(D_{4}\right)$ was not effective $\left(\mathrm{K}_{\mathrm{y}}<1\right)$.

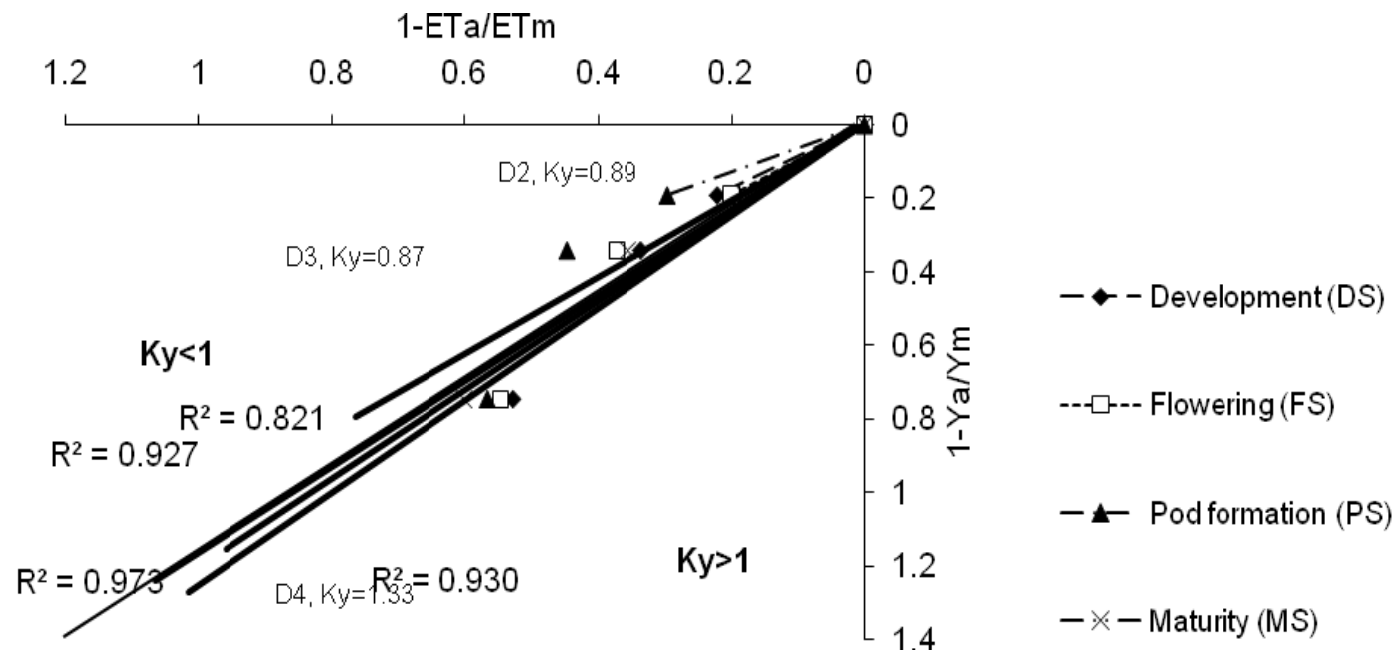

Fig. 6. The effect of available water deficit levels on yield response factor (Ky) at individual growth stages of soybean. 